\title{
Both total and phosphorylated tau are increased in Alzheimer's disease
}

M Sjögren, P Davidsson, M Tullberg, L Minthon, A Wallin, C Wikkelso, A-K Granérus, $\mathrm{H}$ Vanderstichele, E Vanmechelen, K Blennow

Institute of Clinical

Neuroscience,

Göteborg University,

Sahlgrenska University

Hospital / Mölndal,

Sweden

M Sjögren

P Davidsson

M Tullberg

A Wallin

C Wikkelso

K Blennow

Department of Community Medicine,

Lund University,

Neuropsychiatric

Clinic, Malmö

University Hospital,

Malmö, Sweden

L Minthon

Department of

Geriatrics, University

of Health Sciences,

Linköping, Sweden

A-K Granérus

Innogenetics, Ghent,

Belgium

H Vanderstichele

E Vanmechelen

Medical Research

Council, Sweden

K Blennow

Correspondence to: Dr M Sjögren, Institute of

Clinical Neuroscience,

Sahlgrenska

Universitetssjukhuset

Mölndal, SE 43180

Mölndal, Sweden

magnus.sjogren@medfak.gu.se

Received 6 October 2000

and in revised form

15 December 2000

Accepted 19 December 2000

Table 1 Clinical characteristics

\begin{tabular}{lllllll}
\hline Diagnosis & No & $\begin{array}{l}\text { Sex } \\
\text { (M:F) }\end{array}$ & Age $(y)$ & $\begin{array}{l}\text { Duration } \\
\text { dementia }(y)\end{array}$ & MMSE score & Albumin ratio \\
\hline FTD & 18 & $5: 13$ & $65.5(8.4)$ & $4.1(3.2)$ & $17.7(6.4)$ & $9.7(2.9)$ \\
Probable AD & 41 & $13: 28$ & $73.8(5.9)$ & $3.2(1.8)$ & $17.6(5.2)$ & $5.4(1.8)$ \\
Possible AD & 19 & $11: 8$ & $78.9(5.7)$ & $3.0(2.3)$ & $21.9(3.7)$ & $7.9(2.9)$ \\
SAE & 17 & $12: 5$ & $75.8(4.4)$ & $2.6(2.2)$ & $22.1(7.2)$ & $11.9(7.2)$ \\
PD & 15 & $11: 4$ & $69.9(7.5)$ & - & - & $6.8(2.4)$ \\
Controls & 17 & $4: 13$ & $71.8(4.2)$ & - & - & $5.3(1.8)$ \\
\hline
\end{tabular}

Values are means (SD). FTD=Frontotemporal dementia; $\mathrm{AD}=$ Alzheimer's disease; $\mathrm{SAE}=$ subcortical arteriosclerotic encephalopathy; $\mathrm{PD}=$ Parkinson's disease; albumin ratio $=\mathrm{CSF}$ albumin $(\mathrm{mg} / \mathrm{l}) /$ serum albumin $(\mathrm{g} / \mathrm{l})$.

Objectives-To investigate the nature of tau protein in CSF and the involvement of total CSF tau and phosphorylated CSF tau (phosphotau) in various types of dementia.

Methods-Using ELISAs for total tau and tau phosphorylated at Thr181 (phosphotau), the CSF concentrations of total tau and phosphotau were determined in patients with probable and possible AD $(n=41$ and 19, respectively), FTD $(n=18)$, SAE (n=17), and Parkinson's disease (PD; $n=15)$ and in age matched controls $(n=17)$. All the antibodies stained the lower molecular weight bands, whereas only the antibodies that recognise phosphorylated tau stained the higher molecular bands.

Results-Both CSF tau and CSF phosphotau were increased in probable AD compared with FTD $(\mathrm{p}<0.001)$, SAE $(p<0.001)$, PD $(p<0.001)$, and controls $(\mathrm{p}<0.001)$. CSF phosphotau was increased in possible AD compared with FTD $(p<0.001)$ and SAE $(p<0.001)$. CSF tau and CSF phosphotau were positively correlated in all the groups. Molecular weight forms of tau ranging from $25 \mathrm{kDa}$ to 80 kDa were found in the CSF

Conclusion-Both phosphorylated and unphosphorylated tau isoforms were present in the CSF, and tau protein appeared in both truncated and full length forms. The results suggest that the CSF

\begin{abstract}
Backround-Pathological tau protein concentrations in CSF are found in both Alzheimer's disease (AD) and frontotemporal dementia (FTD), but studies on brain tissue have suggested that the tau pathology in AD differs from that in FTD and that the difference may be related to the degree of phosphorylation. As CSF tau protein is increased after stroke, tau may also be implicated in the pathophysiology of vascular dementia, of which subcortical arteriosclerotic encephalopathy (SAE) is a putative subtype.
\end{abstract}


59-82 years), and 17 controls (age range 68-80 years). Their characteristics are summarised in table 1 . All patients included in the study had a clinical diagnosis of FTD, AD, SAE, or PD and were consecutively recruited from prospective longitudinal studies of patients with dementia or PD. Clinical diagnoses were established and CSF sampling was performed. Then neurochemical analyses were performed at the Institute of Clinical Neuroscience, Sahlgrenska University Hospital, Mölndal. Excluded were patients with unspecified dementia (for example, mixed dementia), psychiatric disease (for example, schizophrenia), chronic alcoholism, distinct non-degenerative neurological disease (for example, normal pressure hydrocephalus), a history of severe head injury, infections in the CNS or systemic diseases (for example, malignant tumours) or secondary causes (for example, hypothyroidism) of dementia according to the diagnostic and statistical manual of mental disorders, 3rd ed, revised (DSM-III-R) ${ }^{18}$ or biochemical criteria. Patients with large cerebral infarcts or multiple lacunas (except for the SAE group) were also excluded. All the included patients underwent a thorough clinical investigation, including medical history, physical, neurological and psychiatric examinations, screening laboratory tests of blood (relevant laboratory tests to exclude other causes of dementia for example, hypothyroidism), routine analysis of the CSF (for example, cytology), ECG, chest radiography, EEG, CT or MRI of the brain, investigation of regional cerebral blood flow, using either SPECT or a ${ }^{133} \mathrm{Xe}$ inhalation technique (Cortexplorer). ${ }^{19}$ Diagnosis of FTD was according to the Lund/ Manchester criteria (core diagnostic features) ${ }^{20}$ as previously described. ${ }^{21}$ None of the patients with FTD had signs of infarcts, and only mild white matter changes were found in some patients with FTD. The diagnosis of AD was made by exclusion, in accordance with the NINCDS-ADRDA criteria. ${ }^{22}$ The patients with $\mathrm{AD}$ were divided into one group with probable $\mathrm{AD}$ and another with possible $\mathrm{AD}$, as defined by the NINCDS-ADRDA criteria. The patients with SAE were all referred to a neurological unit specialised in normal pressure hydrocephalus-SAE investigations. The diagnostic criteria for SAE were all of the following: (a) mental deterioration (predominantly asthenoemotional disorder and frontal cognitive dysfunction); (b) gait disturbance (ataxia and/or motor dysfunction); (c) focal neurological signs; (d) vascular risk factors such as hypertension and diabetes or presence of systemic vascular disease; (e) at MRI or CT, bilateral multiple or diffuse subcorticalparaventricular deep white matter changes $(>2$ $\mathrm{mm}$ ), lacunar infarctions, an enlarged ventricular system, and maximum one cortical infarction. The criteria were compatible with those suggested by other studies. ${ }^{23}$ Fifteen of the patients with SAE had no cortical infarction, the remaining four had one. The diagnosis of PD was made in accordance with established clinical and research criteria. ${ }^{24}$ All the patients with PD showed at least two of the three features bradykinesia, rigidity, and resting tremor, and all were responsive to levodopa treatment. No patients with PD showed any signs of dementia, and they all had a mini mental state examination (MMSE) ${ }^{25}$ score of 27 or above. All the clinical diagnoses were made by physicians without knowledge of the results of the biochemical analyses and vice versa. None of the patients were currently treated for dementia (for example, with cholinesterase inhibitors). In the demented patients, the degree of dementia was evaluated using the MMSE. ${ }^{25}$ The control group consisted of subjects without history, symptoms, or signs of psychiatric or neurological disease, malignant disease, or systemic disorders (for example, rheumatoid arthritis, infectious disease). The MMSE was used to evaluate their cognitive status, and those with scores below 28 were excluded. The ethics committee of Göteborg University approved the study. All the patients (or their next of kin) and controls gave their informed consent to participate in the study, which was conducted in accordance with the provisions of the Helsinki Declaration.

\section{CSF ANALYSES}

Lumbar puncture was performed in all the patients and controls. The first $12 \mathrm{ml} \mathrm{CSF}$ was collected in polypropylene tubes and gently mixed to avoid gradient effects. ${ }^{26}$ At the same time, a serum sample was taken. All CSF samples with more than 500 erythrocytes/ $\mu 1$ were excluded. The CSF and serum samples were centrifuged at $2000 \mathrm{~g}$ for 10 minutes to eliminate cells and other insoluble material. Aliquots were then stored at $-80^{\circ} \mathrm{C}$ until biochemical analysis. Quantitative determination of serum and CSF albumin was performed by nephelometry, using a Behring Nephelometer Analyzer (Behringwerke AG, Marburg, Germany). The albumin ratio was calculated as CSF albumin (mg/l)/serum albumin ( $\mathrm{g} / \mathrm{l})$ and was used as a measure of blood-brain barrier function. ${ }^{27} \mathrm{CSF}$ tau was determined using a sandwich ELISA (Innotest hTAU-Ag, Innogenetics, Gent, Belgium), constructed to measure total tau (both normal tau and phosphorylated tau), as described previously in detail. ${ }^{57}$ The phosphotau (P-Thr181) ELISA was essentially designed as the Innotest hTau antigen ELISA, using the same reagents. Briefly, monoclonal antibody (MAb) HT7, which recognises both normal tau and phosphotau, was used as capturing antibody and biotinylated $\mathrm{MAb}$ AT270 (specific to P-Thr181 phosphotau) as detection antibody. ${ }^{28}$

DETERMINATION OF ApoE ISOFORMS

Depending on the sample material available, determination of ApoE isoforms was performed either by isoelectric focusing and western blotting with minor modification $\mathrm{s}^{29}{ }^{30}$ or by polymerised chain reaction and reverse DNA hybridisation using the Innolipa ApoE kit (Innogenetics, Ghent, Belgium).

CHARACTERISATION OF TAU IN THE CSF

To characterise tau protein in CSF, the CSF samples from patients with $\mathrm{AD}$ were used. All the CSF samples had a normal cell count, a 
normal CSF/serum albumin ratio (normal blood-brain barrier function), no signs of intrathecal IgG or IgM production, and CSF tau concentrations above $700 \mathrm{ng} / \mathrm{ml}$. The CSF samples were pooled and stored at $-80^{\circ} \mathrm{C}$ before biochemical analysis. The MAbs for tau protein were generated using tau purified from bovine brain (BT2), normal human brain (HT7), and Alzheimer human brain (AT8, AT120, AT180, and AT 270) as antigen. ${ }^{31}$ $\mathrm{MAb}$ BT2 recognises only unphosphorylated tau protein, ${ }^{31}{ }^{33}$ MAbs HT7 and AT120 both recognise unphosphorylated and phosphorylated tau equally well, ${ }^{5334}$ and MAbs AT8, AT180, and AT270 all are phosphorylation dependent. ${ }^{313335}$ Liquid phase immunelectropheresis was performed with some modifications of experimental procedures, which have been described previously in detail. ${ }^{36} 37$ Human CSF $(80 \mathrm{ml})$ was concentrated fivefold and dialysed (molecular weight cut off 7000) against distilled water. After dialysis, urea (final concentration $6 \mathrm{M}$ ) and dithioerythritol (final concentration $20 \mathrm{mM}$ ) were added, followed by carrier ampholytes (Biolyte ampholytes $\mathrm{pH}$ range 3-10, Bio-Rad) added to a concentration of $2.5 \%$ and the volume was brought up to $18 \mathrm{ml}$ with distilled water. The Rotofor apparatus (Bio-Rad) was used in compliance with the manufacturer's instruction. The sample $(18 \mathrm{ml})$ was loaded into the mini Rotofor cell for initial fractionation in a wide range $\mathrm{pH}$ gradient $(\mathrm{pH} 3-10)$. Constant power $(10 \mathrm{~W})$ was applied for 4 hours with the system cooled to $4^{\circ} \mathrm{C}$. Twenty separate isoelectric focusing fractions were rapidly harvested and $\mathrm{pH}$ values were determined immediately. The presence of tau protein in the harvested Rotofor fractions was determined by western blotting using several antibodies to tau protein. A $300 \mu \mathrm{l}$ aliquot of each Rotofor fraction was concentrated fivefold by vacuum centrifugation. The fractions were electrophoresed through a $10 \%$ NU-PAGE minigel using the MOPS buffer system (Novex). The proteins were transferred from the gel onto a polyvinyl difluoride (PVDF) membrane (Millipore) by a semi-dry technique using the NovaBlot System (Pharmacia) at $0.8 \mathrm{~mA} / \mathrm{cm}^{2}$ for 40 minutes and were then blocked with $5 \%$ milk powder in phosphate buffered saline ( 58 $\mathrm{mM} \mathrm{Na} \mathrm{HPO}_{4} 2 \mathrm{H}_{2} \mathrm{O}, 17 \mathrm{mM} \mathrm{Na} \mathrm{PO}_{4} \mathrm{H}_{2} \mathrm{O}, 68$ $\mathrm{mM} \mathrm{NaCl}, \mathrm{pH} 7.4$ ), containing $0.05 \%$ Tween20. The membrane was incubated overnight with MAbs to tau protein (HT7, BT2, AT120, AT270, AT8), diluted to $1 \mathrm{pg} / \mathrm{ml}$. After washing, the membrane was incubated with alkaline phosphatase conjugated goat antimouse antibody (Jackson) diluted 1/3000 for 1 hour and the colour reaction was developed with $0.015 \%$ 5-bromo-4-chloro-3-indolyl phosphate and $0.030 \%$ nitro blue tetrazolium in $0.1 \mathrm{M}$ carbonate buffer containing $1.0 \mathrm{mM}$ $\mathrm{MgCl}_{2} \cdot{ }^{38}$ For detection of the biotinylated antibodies (HT7), the membrane was incubated with alkaline phosphatase conjugated extravidin (Sigma).
STATISTICAL ANALYSIS FOR THE GROUP COMPARISONS

All the variables were normally distributed and therefore parametric statistics were used for group comparisons of the effect variables (CSF tau and CSF phosphotau). A fully factorial multiple analysis of variance (ANOVA) was performed with CSF tau and CSF phosphotau as dependent variables, age, duration and severity of dementia as covariates, and diagnostic category (probable and possible AD, FTD, PD, SAE, and normal aging) as factor. Factors that did not contribute to the variance were excluded from the analysis and recalculation was performed. Post hoc comparisons were performed using Tukey's post hoc test for unequal numbers. Pearson's $\chi^{2}$ test was used for comparisons of ApoE4 allele frequency between the groups. Pearson's correlation test was used for calculation of correlations. For the calculation of the sensitivity and specificity of CSF tau and CSF phosphotau, a cut off was determined at the mean value $+2 \mathrm{SD}$ in the control group. ${ }^{39}$

\section{Results}

The mean age was significantly lower in PD $(\mathrm{p}<0.001)$ and probable AD $(\mathrm{p}<0.05)$ compared with possible AD. The patients with probable $\mathrm{AD}$ were significantly more demented than those with possible AD $(p<0.05)$. No differences were found between any of the patient or control groups for the CSF/serum albumin ratio (for the dementia groups only) and sex (table 1). CSF tau was significantly increased in probable $\mathrm{AD}$ and possible $\mathrm{AD}$ compared with FTD $(\mathrm{p}<0.001)$, SAE $(\mathrm{p}<0.001)$, PD $(p<0.001)$, and controls $(p<0.001)$ and in FTD compared with SAE ( $\mathrm{p}<0.01$, table 2 and fig 1). A specificity of $95 \%$ (cut off $12.5 \mathrm{pM}$ ) gave a sensitivity of $85.4 \%$ for probable AD and $84.2 \%$ for possible AD. Furthermore, it separated AD from FTD with a specificity of $88.9 \%$, SAE $100 \%$, and PD $100 \%$. CSF phosphotau was significantly increased in probable AD compared with FTD $(p<0.001)$, SAE $(\mathrm{p}<0.001), \quad P D \quad(p<0.001)$, and controls $(\mathrm{p}<0.001)$ and in possible AD compared with FTD $(p<0.001)$ and SAE $(p<0.001)$, but not compared with controls. Furthermore, CSF phosphotau was also significantly decreased in FTD $(\mathrm{p}<0.05)$ and SAE $(\mathrm{p}<0.05)$ compared with controls (table 2 and fig 2). A specificity of $95 \%$ (cut off $22.6 \mathrm{pM}$ ) gave a sensitivity of

Table 2 CSF concentrations of tau and phosphotau in a group of patients with various dementia disorders, Parkinsons's disease, and normal aging

\begin{tabular}{lll}
\hline \multirow{2}{*}{ Diagnosis } & \multicolumn{2}{l}{ CSF concentrations $(p M)$} \\
\cline { 2 - 3 } & Tau & Phosphotau \\
\hline FTD & $9.74(2.88)$ & $8.59(3.88)$ \\
Probable AD & $20.01(7.58)^{\star \star \star}$ & $23.12(10.10)^{\star \star \star}$ \\
Possible AD & $16.34(4.30)^{\star \star \star}$ & $18.01(5.86)$ \\
SAE & $3.70(2.29)$ & $6.39(5.59)$ \\
PD & $7.45(1.59)$ & $14.07(3.11)$ \\
Controls & $8.33(2.83)$ & $15.92(5.72)$ \\
\hline
\end{tabular}

Values are means (SD). FTD=Frontotemporal dementia, $\mathrm{AD}=$ Alzheimer's disease; $\mathrm{SAE}=$ subcortical arteriosclerotic encephalopathy; $\mathrm{PD}=$ Parkinson's disease; tau=total tau protein; phosphotau=phosphorylated tau. ${ }^{\star \star \star}$ p $<0.001$ (referring to statistical difference between marked group and controls). 


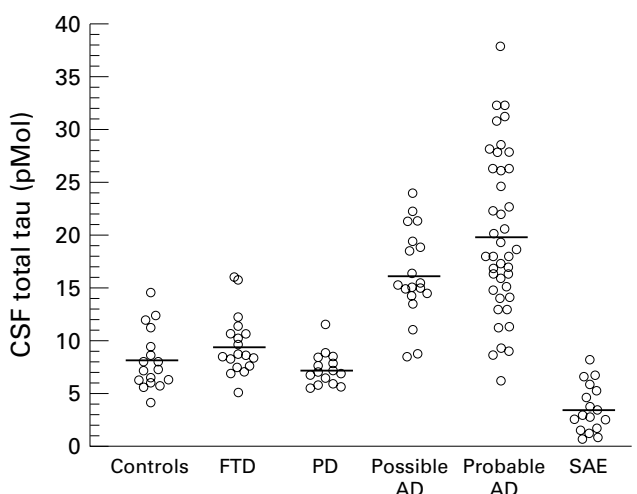

Figure 1 Scatterplot of CSF tau in a group of patients with various types of dementia, Parkinson's disease, and normal aging. FTD =frontotemporal dementia, $P D=$ Parkinson's disease, $A D=$ Alzheimer's disease, $S A E=$ subcortical arteriosclerotic encephalopathy.

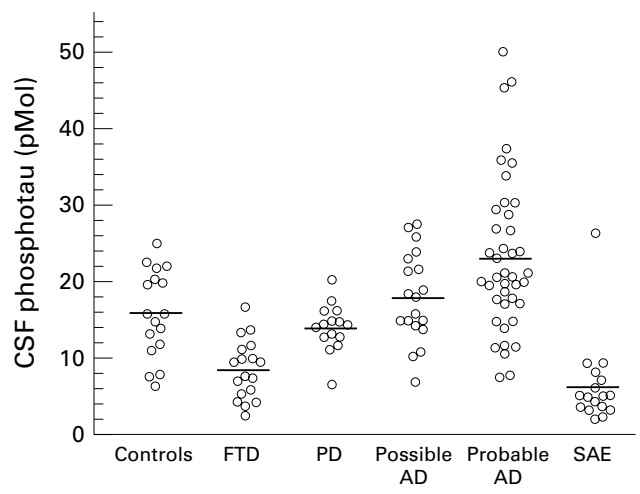

Figure 2 Scatterplot of CSF phosphotau in a group of patients with various types of dementia, Parkinson's disease, and normal aging. Abbreviations as in fig 1.

$43.9 \%$ for probable $\mathrm{AD}$ and $26.3 \%$ for possible AD. Furthermore, it separated AD from FTD with a specificity of $100 \%$, SAE $94.1 \%$, and PD $100 \%$. CSF tau and CSF phosphotau were positively correlated in all diagnostic groups (probable and possible AD $r=0.86, \mathrm{p}<0.001$; FTD $r=0.66, \mathrm{p}<0.01$; SAE $r=0.58, \mathrm{p}<0.05$; PD $r=0.62, \mathrm{p}<0.05$; controls $\mathrm{r}=0.65 ; \mathrm{p}<0.01$, fig 3). No significant differences in the CSF concentrations of tau and phosphotau were found between the patients possessing and those lacking the ApoE4 allele when calculating each group separately $(\mathrm{AD}, \mathrm{ApoE} 4$ allele

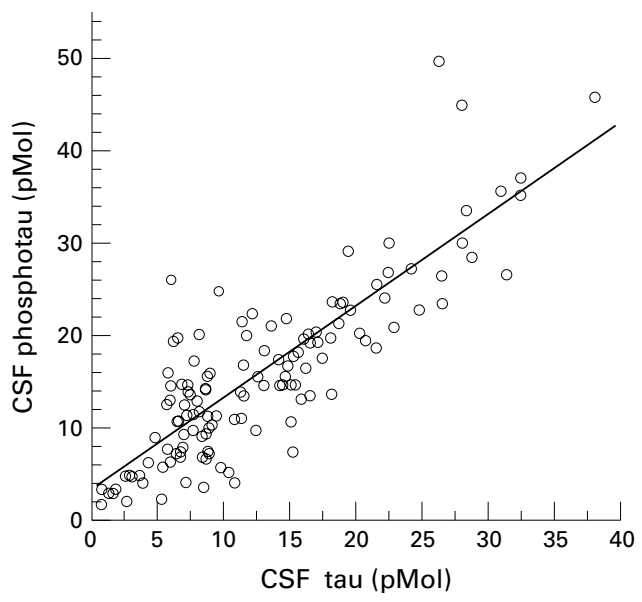

Figure 3 Plot of correlation between CSF tau and CSF phosphotau, with all subjects in the study included.

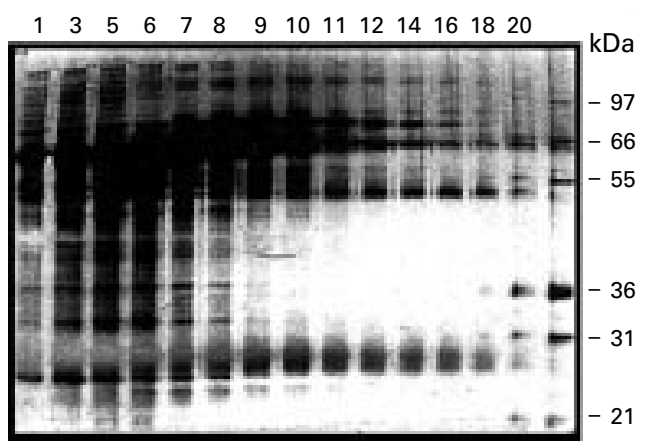

Figure 4 Isoelectric focusing fractions of a pooled CSF sample. The sample, consisting of $80 \mathrm{ml} C S F$, was concentrated fivefold and dialysed. Urea (final concentration 6M), DTT (final concentration $20 \mathrm{mM}$ ) and $2.5 \%$ biolyte, $p H$ range $3-10$, were added. The CSF protein sample was loaded onto the Rotafor cell and run at $10 \mathrm{~W}$ constant power. Twenty fractions were harvested. Some of the fractions were analysed by the NuPAGE system and silver stained. The molecular weight standard (Mark 12, Novex, San Diego, CA, USA) was used.

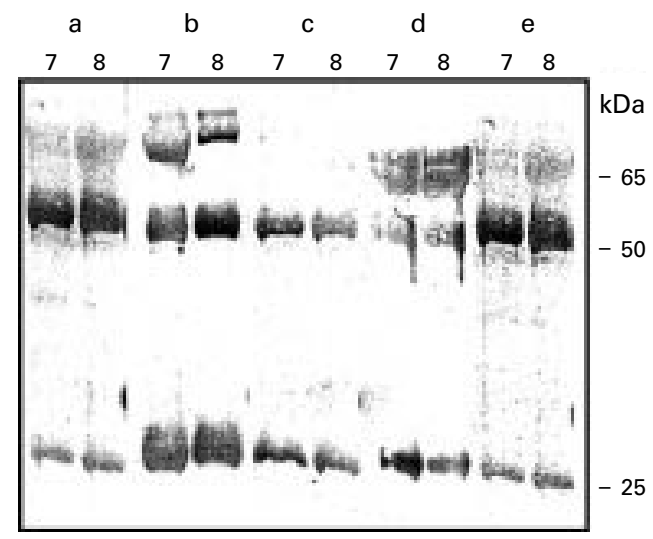

Figure 5 SDS-PAGE and immunoblotting of Rotofor fractions 7 and 8. $300 \mu$ l aliquots of Rotofor fractions 7 and 8 were concentrated fivefold by vacuum centrifugation and analysed by the NuPAGE system followed by immunoblotting using antibodies a/HT7; b/AT120; c/BT2; d/AT270; e/AT8.

positive $v$ ApoE4 allele negative: CSF tau 20.1(7.1) v 17.2 (6.6); CSF phosphotau 21.9 (8.3) $v 21.1(8.3)$ ). The ApoE4 allele was found in $73 \%$ of patients with probable $\mathrm{AD}, 42 \%$ of patients with possible $\mathrm{AD}, 46 \%$ of patients with FTD, and in $8 \%$ of controls. Information on the presence of ApoE4 alleles in SAE and PD was not available. In probable $\mathrm{AD}$, a negative correlation was found between age and CSF tau $(r=-0.37, \mathrm{p}<0.05)$ and between age at onset and CSF tau $(r=-0.35, \mathrm{p}<0.05)$. In PD, a positive correlation was found between age and the albumin ratio $(r=0.42, \mathrm{p}<0.01)$. The pooled CSF sample used for characterisation of tau had a volume of $80 \mathrm{ml}$ and contained about $300 \mathrm{mg} / \mathrm{l}$ albumin. About $80 \%$ of the proteins were albumin and immunoglobulins and the other $20 \%$ a complex mixture of proteins, each present in CSF in a low concentration, as shown by the silver staining of the isoelectric focusing fractions (fig 4). The initial 
concentration of tau was $700 \mathrm{ng} / \mathrm{ml}$, as measured by a specific sandwich ELISA. Western blot analysis of the isoelectric focusing fractions indicated that most of the proteins were focused in fractions 6-12, corresponding to a $\mathrm{pH}$ range of 6.5-8.5. Western blot analysis of the Rotofor fractions demonstrated two immunoreactive bands with molecular weights of $25 \mathrm{kDa}$ and $52 \mathrm{kDa}$ and several bands with molecular weights in the range of $65-80 \mathrm{kDa}$. Omission of the primary antibodies (using only the secondary antibody) gave no visible bands on the blots. The former bands were stained by all five MAbs (fig 5). The immunoreactive bands in the range of $65-80 \mathrm{kDa}$ were detected using HT7, AT120, AT270, and AT8 antibodies, but they were not detected using the BT2 antibody (fig 5).

\section{Discussion}

The results of the present study suggest that both CSF tau and CSF phosphotau are increased in $\mathrm{AD}$ but not in FTD, SAE, PD, or normal aging. The finding of high CSF tau in $\mathrm{AD}$ is in agreement with several previous studies. ${ }^{113940}$ The finding of increased CSF phosphotau in $\mathrm{AD}$ is also in agreement with previous studies. ${ }^{71}$ However, ELISAs specific to different phosphorylated epitopes on tau have been used in these studies. One study used an ELISA reacting with both P-Thr181 and P-Thr231, ${ }^{7}$ whereas another study used an ELISA specific to P-Thr $231^{41}$ and the present study used an ELISA specific to P-Thr 181. Thus, both total tau and tau phosphorylated at different epitopes have been shown to be increased in the CSF in AD. To further examine the nature of tau in CSF, we used five different anti-tau antibodies, directed against both phosphorylated and unphosphorylated epitopes. All five antibodies labelled two immunoreactive bands of $\sim 52 \mathrm{kDa}$ and 25 $\mathrm{kDa}$, suggesting that these two bands contain both phosphorylated and unphosphorylated tau. The higher molecular weight bands of $\sim 65-80 \mathrm{kDa}$ were not reactive to the BT2 antibody, which only recognises unphosphorylated tau, suggesting that the higher molecular weight bands in the CSF contain phosphorylated isoforms of tau. Normal tau demonstrated an apparent molecular weight of 48-68 $\mathrm{kDa}$ in human brain. The CSF-tau isoforms migrating at $52 \mathrm{kDa}$ and $65-80 \mathrm{kDa}$ occur in both CSF and postmortem brain. The low molecular weight of the tau isoform migrating at $25 \mathrm{kDa}$ suggests that this form of tau is truncated, and the finding that all the antibodies recognised it suggests that it contains an internal domain of the intact protein. The nature of tau in CSF has not been well documented. Previous studies have found inconsistent results for the molecular weight of tau in the CSF in $\mathrm{AD}$, with variations such as $68 \mathrm{kDa},{ }^{42} 55$ $\mathrm{kDa},{ }^{11}$ three bands of $50-65 \mathrm{kDa},{ }^{6}$ one band of $26-28 \mathrm{kDa}^{43}$ in lumbar CSF, and several bands in the range of $30 \sim 50 \mathrm{kDa}$ in ventricular $\mathrm{CSF}^{44}$ These differences may reflect technical differences including the use of different tau antibodies. Further, the low concentrations of tau in the CSF make detection difficult. As neuron specific proteins are present in the $\mathrm{pg} / \mathrm{ml}$ range, it is uncertain whether western blot positive proteins can be detected in $50 \mu \mathrm{l}$ CSF. One study used $6 \mathrm{ml} \mathrm{CSF}$ for western blot, ${ }^{11}$ and another used 3-50 $\mu \mathrm{CSF} .^{44}$ Immunoprecipitated CSF has also been used to detect tau in $\mathrm{CSF}^{43}$ We were unable to detect tau by western blotting alone, even after concentration of the CSF. For analysis of proteins present in trace concentrations, elimination of plasma proteins, especially albumin, by different chromatographic or electrophoretic methods may greatly enhance the sensitivity for CNS specific proteins and decrease nonspecific binding. ${ }^{36}{ }^{37}$ The major advantage of liquid phase isoelectric focusing is that it enables the detection of low abundance proteins, such as tau in CSF. ${ }^{37}$ We determined whether the increases in CSF tau and CSF phosphotau occurred early in the course of the disease in AD. Our finding of no correlation between degree of dementia and CSF tau or CSF phosphotau suggests that the increases in tau and phosphotau are initial events in the pathogenesis of $\mathrm{AD}$ and may thus be regarded as trait markers rather than markers of the state of disease. CSF tau was normal and CSF phosphotau decreased in FTD. This suggests that the neuronal and axonal damage is more limited in FTD than in AD or, possibly, that the location of the pathology in the frontal lobe in FTD is less well reflected by CSF analyses than the temporoparietal and especially the medial temporal pathology in AD. Decreased CSF phosphotau concentrations may possibly be explained by disturbances in the mechanisms that regulate the phosphorylation of tau and this has to be investigated further. Moreover, this also suggests that CSF tau and CSF phosphotau may be used to improve the differential diagnosis of FTD from AD. However, previous studies using only CSF tau have presented discrepant results, showing either increased $^{71213}$ or normal CSF tau concentrations in FTD. ${ }^{14}{ }^{15}$ The cause of the discrepant results is difficult to explain. As all these studies were clinical and thus no or only few neuropathological diagnoses have been established, misdiagnosis might have influenced the results. Alternative explanations include methodological differences. The CSF concentrations of tau was normal in SAE, in agreement with some previous studies of patients with vascular dementia, ${ }^{69}$ but at variance with other studies that have found increased tau concentrations. ${ }^{737}$ As none of the patients with SAE in the present study had single stroke related dementia, the reported increased tau concentrations may be due to extensive axonal damage produced by major stroke events. Furthermore, the CSF concentrations of both tau and phosphotau in SAE showed a low variance, which might be a reflection of the increased distribution volume of CSF, resulting in the enlarged ventricles, preferentally found in patients with SAE. The latter may also explain why CSF phosphotau was decreased in SAE, but it may also be due to disturbances in the mechanisms that regulate the phosphorylation of tau. In PD, the normal concentrations of 
both CSF tau and CSF phosphotau are in agreement with previous reports ${ }^{7}{ }^{15}$ and suggest pathophysiological discrepancies between the common neurodegenerative disorders $\mathrm{AD}$ and PD. Furthermore, as both CSF tau and CSF phosphotau separated AD from PD, they may be used in the differential diagnosis between these disorders. No differences in CSF tau or CSF phosphotau were found between patients with $\mathrm{AD}$ possessing and those lacking the ApoE4 allele, suggesting that ApoE4, although it is a risk factor for AD, does not affect the expression of tau or the shedding of tau to the CSF in AD. The mechanism for the increase in both CSF tau and CSF phosphotau is unclear. Studies on brain homogenates in AD have found increased cortical concentrations of phosphotau, ${ }^{314246475051}$ but reduced concentrations of normal tau. ${ }^{48} 4951$ These findings are also consistent with studies reporting that the tau mRNA concentration is unchanged in $\mathrm{AD},{ }^{52}{ }^{53}$ altogether suggesting that hyperphosphorylation of tau rather than an increased synthesis of tau protein is one of the preponderant pathophysiological mechanisms in AD. One possible explanation is that, as a result of the neuronal/ axonal degeneration in $\mathrm{AD}$, both normal tau and phosphotau are shed into the CSF from degenerating neurons, resulting in increased CSF concentrations of both forms of tau. The high correlation between CSF tau and CSF phosphotau supports this suggestion, which also is concordant with the findings in $\mathrm{AD}$ brain, as discussed above. However, it should be remembered that the methods used to determine CSF tau and CSF phosphotau are not directly comparable, as they use different antibodies for detection of the protein in question. Interestingly, the electrophoretic mobility of phosphotau in the brain differs between AD and Pick's disease (one of the FTD disorders), with a triplet of 55,64, and $69 \mathrm{kDa}$ in $\mathrm{AD}$ and a doublet of 55 and $64 \mathrm{kDa}$ in Pick's disease. Further, smears of tau aggregates are always found in $\mathrm{AD}$ but are absent in FTD. ${ }^{4}$ The isoelectric point also differs between $\mathrm{AD}$ and Pick's disease, further supporting the idea that tau in these disorders is differentially phosphorylated. ${ }^{4}$ Thus, it is possible that ELISAs specific to other phosphorylated epitopes of tau may show more differences between $\mathrm{AD}$ and FTD. Taken together, increased CSF concentrations of tau and phosphotau are found in two thirds of patients with probable $\mathrm{AD}$ and in about half of those with possible AD, but normal concentrations are found in FTD, PD, and SAE compared with normal aging. This probably reflects that different pathophysiological mechanisms are active in the various neurodegenerative disorders. Values in the normal range do not exclude AD. Further studies are needed to explore the diagnostic and pathogenic potential of CSF phosphotau measurements.

This work was supported by grants from Alzheimerfonden; Bohuslandstingets FoU fond; Fredrik och Ingrid Thurings Stif-
telse; Martina och Wilhelm Lundgrens Stiftelse; Stiftelsen för telse; Martina och Wilhelm Lundgrens Stiftelse; Stiftelsen för
Gamla Tjänarinnor; Stiftelsen Handlanden Hjalmar Svenssons
Forskningsfond; Stiftelsen Lars Hiertas Minne; Lundbeckfonden; and the Swedish Medical Society; the Swedish Medical Research Council (grants 12103,11560, 12769, 13121 and 09946). We are grateful to Mrs Ewa Styrud and Maria Lindbjer or technical assistance.

1 Tomlinson BE, Corsellis JAN. Ageing and the dementias. In: Hume Adams J, Corsellis JAN, Duchen LW, eds. Greenfield's neuropathology. London: Edward Arnold; 984:951-1025

2 Spillantini MG, Goedert M. Tau protein pathology in neurodegenerative diseases. Trends Neurosci 1998;21:428-33.

3 Vermersch P, Bordet R, Ledoze F, et al. Demonstration of a specific profile of pathological tau proteins in frontotemporal dementia cases. CR Acad Sci 1995;318:439-45.

4 Delacourte A, Buée L, Vermersch P. Immunochemistry in frontotemporal dementia. In: Pasquier F, Lebert F, Scheltens P, eds. Frontotemporal dementia. Dordrecht: ICG Publications, 1996:115-24.

5 Vandermeeren $M$, Mercken $M$, Vanmechelen E, et al. Detection of tau proteins in normal and Alzheimer's disease cerebrospinal fluid with a sensitive sandwich enzyme-linked immunosorbent assay. $f$ Neurochem 1993; 61:1828-34.

6 Arai H, Terajima M, Miura M, et al. Tau in cerebrospinal fluid: a potential diagnostic marker in Alzheimer's disease. Ann Neurol 1995;38:649-52.

7 Blennow K, Wallin A, Agren H, et al. Tau protein in cerebrospinal fluid: a biochemical marker for axonal degeneration in Alzheimer disease? Mol Chem Neuropathol 1995;26:231-45

8 Jensen M, Basun H, Lannfelt L. Increased cerebrospinal fluid tau in patients with Alzheimer's disease. Neurosci Lett 1995;186:189-91

9 Mori H, Hosoda K, Matsubara E, et al. Tau in cerebrospinal fluids: establishment of the sandwich ELISA with antibody specific to the repeat sequence in tau. Neurosci Lett 1995;186:181-3.

10 Motter R, Vigo Pelfrey C, Kholodenko D, et al. Reduction of $\beta$-amyloid peptide 42 in the cerebrospinal fluid of patients with Alzheimer's disease. Ann Neurol 1995;38: 643-8.

11 Vigo-Pelfrey C, Seubert P, Barbour R, et al. Elevation of microtubule-associated protein tau in the cerebrospinal microtubule-associated protein tau in the cerebrospinal fluid of patients

12 Arai H, Morikawa Y, Higuchi M, et al. Cerebrospinal fluid tau levels in neurodegenerative diseases with distinct tau-related pathology. Biochem Biophys Res Commun 1997; 236:262-4.

3 Green AJ, Harvey RJ, Thompson EJ, et al. Increased tau in the cerebrospinal fluid of patients with frontotemporal dementia and Alzheimer's disease. Neurosci Lett 1999;259: 133-5.

14 Mecocci $\mathrm{P}$, Cherubini A, Bregnocchi M, et al. Tau protein in cerebrospinal fluid: a new diagnostic and prognostic marker in Alzheimer disease? Alzheimer Dis Assoc Disord 1998;12:211-14.

15 Siögren M, Minthon L, Davidsson P, et al. CSF levels of tau, $\beta$-amyloid 42 and GAP-43 in frontotemporal dementia, other types of dementia and normal aging. F Neural transm 2000;105:563-79.

16 Hutton M, Lendon CL, Rizzu P, et al. Association of missense and 5'-splice-site mutations in tau with the inherited dementia FTDP-17. Nature 1998;393:702-5.

17 Tullberg M, Månsson JE, Fredman $\mathrm{P}$, et al. CSF sulfatide distinguishes between normal pressure hydrocephalus and subcortical arteriosclerotic encephalopathy. $\mathcal{F}$ Neurol Neurosurg Psychiatry 2000;69:74-81.

18 American Psychiatric Association. Diagnostic and statistical manual of mental disorders, 3rd ed, revised. Washington, DC: Cambridge University Press; 1987.

19 Risberg J, Gustafson L. 133Xe cerebral blood flow in dementia and in neuropsychiatry research. In: Magistretti PL, ed. Functional radionuclide imaging of the brain. New York: Raven Press; 1983:151-9

20 Brun A, Englund B, Gustafsson L, et al. clinical and neuropathological criteria for frontotemporal dementia. $f$ Neurol Neurosurg Psychiatry 1994;57:416-18.

21 Sjögren M, Edman Â, Wallin A. Symptomatological characteristics distinguish between frontotemporal dementia and vascular dementia with a dominating frontal lobe syndrome. Int f Geriatr Psychiatry 1997;12:656-61.

22 McKhann G, Drachman D, Folstein M, et al. Clinical diagnosis of Alzheimer's disease: report on the NINCDSADRDA Work group under the auspices of department of health and human services task force on Alzheimer's disease. Neurology 1984;34:939-44

23 Bennett DA, Wilson RS, Gilley DW, et al. Clinical diagnosis of Binswanger's disease. $\mathcal{F}$ Neurol Neurosurg Psychiatry 1990;53:961-5.

24 Wallin ACJ, Granérus A-K. Prevalence of dementia and regional brain syndromes in long-standing Parkinson's disease. Parkinsonism and Related Disorders 1999;5:103-10.

25 Folstein M, Folstein S, McHugh P. Mini-mental state, a practical method for grading the cognitive state of patients for the clinician. F Psychol Res 1975;12:189-98.

26 Blennow K, Fredman P, Wallin A, et al. Protein analysis in cerebrospinal fluid: I. Influence of concentration gradients for proteins on cerebrospinal fluid/serum albumin ratio. Eur Neurology 1993;33:126-8.

27 Tibbling G, Link H, Ohman S. Principles of albumin and IgG analyses in neurological disorders. I. Establishment of reference values. Scand $尹$ Clin Lab Invest 1977;37:385-90. 
28 Vanmechelen E, Vanderstichele H, Davidsson $\mathrm{P}$, et al. Quantification of tau phosphorylated at threonine 181 in human cerebrospinal fluid: a sandwich ELISA with a synthetic phosphop

29 Kane JW, Gowland E. A method for the identification of apolipoprotein $\mathrm{E}$ isoforms employing chemical precipitation and flat bed isoelectric focusing in agarose. Ann Clin Biochem 1986;23:509-13.

30 Skoog I, Vanmechelen E, Andreasson LA, et al. A population-based study of tau protein and ubiquitin in cerebrospinal fluid in 85 year olds: relation to severity of dementia and cerebral atrophy, but not to the apolipoprotein E4 allele. Neurodegeneration 1995;4:433-42.

31 Mercken M, Vandermeeren M, Lubke U, et al. Monoclonal antibodies with selective specificity for Alzheimer tau are directed against phosphatase-sensitive epitopes. Acta Neuropathol Berl 1992;84:265-72.

32 Mercken $M$, Vandermeeren $M$, Lubke $U$, et al. Affinity purification of human tau proteins and the construction of purification of human tau proteins and the construction of for human tau detection. F Neurochem 1992;58:548-53.

33 Goedert M, Jakes R, Crowther RA, et al. Epitope mapping of monoclonal antibodies to the paired helical filaments of Alzheimer's disease: identification of phosphorylation sites in tau protein. Biochem f 1994;301:871-7.

34 Goedert M, Jakes R, Crowther RA, et al. The abnorma phosphorylation of tau at Ser-202 in Alzheimer's disease recapitulates phosphorylation during development. Proc Natl Acad Sci 1993;90:5066-70.

35 Goedert M, Jakes R, Vanmechelen E. Monoclonal antibody AT8 recognises tau protein phosphorylated at both serine 202 and threonine 205. Neurosci Lett 1995;189:167-9.

36 Davidsson P, Westman A, Puchades M, et al. Characterization of proteins from human cerebrospinal fluid by a combination of preparative two dimensional liquid phase electrophoresis and matrix assisted laser desorption/ ionization time of flight mass spectrometry. Anal Chem 10nization time of

37 Davidsson P, Puchades M, Blennow K. Identification of synaptic vesicle, pre and postsynaptic proteins in human cerebrospinal fluid using liquid phase isoelectric focusing. cerebrospinal fluid using liquid

38 Leary JJ, Brigati DJ, Ward DC. Rapid and sensitive colorimetric method for visualizing biotin labeled DNA probes hybridized to DNA or RNA immobilized in nitrocellulose bio-plots. Proc Natl Acad Sci (USA) 1983;80:4045-9.

39 Andreasen N, Vanmechelen E, Van de Voorde A, et al. Cerebrospinal fluid tau protein as a biochemical marker for Alzheimer's disease: a community based follow up study. $\mathscr{F}$ Neurol Neurosurg Psychiatry 1998;64:298-305.

40 Galasko D, Chang L, Motter R, et al. High cerebrospinal fluid tau and low amyloid $\beta 42$ levels in the clinical diagnosis of Alzheimer disease and relation to apolipoprotein $\mathrm{E}$ genotype. Arch Neurol 1998;55:937-45.
41 Ishiguro $\mathrm{K}$, Ohno $\mathrm{H}$, Arai $\mathrm{H}$, et al. Phosphorylated tau in human cerebrospinal fluid is a diagnostic marker for human cerebrospinal fluid is a diagnostic mark

42 Wolozin B, Davies P. Alzheimer's related neuronal protein A68: specificity and distibution. Ann Neurol 1987;22:5216.

43 Johnson GV, Seubert P, Cox TM, et al. The tau protein in human cerebrospinal fluid in Alzheimer's disease consists of proteolytically derived fragments. $\mathcal{F}$ Neurochem 1997;68: 430-3.

44 Zemlan FP, Rosenberg WS, Luebbe PA, et al. Quantification of axonal damage in traumatic brain injury: affinity purification and characterization of cerebrospinal fluid tau proteins. I Neurochem 1999;72:741-50.

45 Molina JA, Benito-Leon J, Jimenez-Jimenez FJ, et al. Tau protein concentrations in cerebrospinal fluid of nondemented Parkinson's disease patients. Neurosci Lett 1997; 238:139-41

46 Bissette G, Smith WH, Dole KC, et al. Alterations in Alzheimer's disease-associated protein in Alzheimer's disease frontal and temporal cortex. Arch Gen Psychiatry 1991;48:1009-12.

47 Harrington CR, Mukeatova-Ladinska EB, Hills R, et al. Measurement of distinct immunochemical presentations of tau protein in Alzheimer disease. Proc Natl Acad Sci 1991; 88:5842-6.

48 Mukaetova-Ladinska EB, Harrington CR, Hills R, et al. Regional distribution of paired helical filaments and normal tau proteins in aging and in Alzheimer's disease with and witho

49 Bramblett GT, Trojanowski JQ, Lee VMY. Regions with abundant neurofibrillary pathology in human brain exhibit a selective reduction in levels of binding component tau and accumulation of abnormal tau-isoforms (A68 proteins). Lab Invest 1992;66:212-22.

50 Khatoon S, Grundke-Iqbal I, Iqbal K. Brain levels of microtubule-associated protein tau are elevated in Alzheimer's disease: a radioimmunoslot-blot assay for nanograms of the protein. $\mathcal{F}$ Neurochem 1992;59:750-3.

51 Harrington CR, Perry RH, Perry EK, et al. Senile dementia of Lewy body type and Alzheimer type are biochemically of Lewy body type and Alzheimer type are biochemically phorylated tau protein. Dementia 1994;5:215-8.

52 Goedert M, Wischik CM, Crowther RA, et al. Cloning and sequencing of the cDNA encoding a core protein of the paired helical filament of Alzheimer disease: identification as the microtubule-associated protein tau. Proc Natl Acad Sci $1988 ; 85: 4051-5$.

53 Oyama F, Shimada H, Oyama R, et al. Differential expression of $\beta$-amyloid protein precursor (APP) and tau mRNA in the aged human brain: individual variability and correlation between APP-751 and four-repeat tau. 7 Neuropathol Exp Neurol 1991;50:560. 